\title{
Article \\ Steel Slag as New Catalyst for the Synthesis of Fames from Soybean Oil
}

\author{
Michele Casiello ${ }^{1}{ }^{\oplus}$, Onofrio Losito ${ }^{1}$, Andrea Aloia ${ }^{1}$, Daniela Caputo ${ }^{1}$, Caterina Fusco ${ }^{2}{ }^{\oplus}$, Rosella Attrotto ${ }^{3}$, \\ Antonio Monopoli ${ }^{1}$, Angelo Nacci ${ }^{1,2}$ (D) and Lucia D'Accolti ${ }^{1,2, *(D)}$ \\ 1 Chemistry Department, University of Bari Aldo Moro, via Orabona 4, 70125 Bari, Italy; \\ michele.casiello@uniba.it (M.C.); o.losito1@studenti.uniba.it (O.L.); a.aloia3@studenti.uniba.it (A.A.); \\ daniela.caputo@uniba.it (D.C.); antonio.monopoli@uniba.it (A.M.); angelo.nacci@uniba.it (A.N.) \\ 2 CNR-Istituto di Chimica dei Composti Organometallici (ICCOM), Bari Section, via Orabona 4, \\ 70126 Bari, Italy; fusco@ba.iccom.cnr.it \\ 3 Research and Development Center, Primary Process Department, ArcelorMittal Italia, Via Appia Km 648, \\ 74121 Taranto, Italy; rosella.attrotto@arcelor.com \\ * Correspondence: lucia.daccolti@uniba.it
}

check for updates

Citation: Casiello, M.; Losito, O.; Aloia, A.; Caputo, D.; Fusco, C.; Attrotto, R.; Monopoli, A.; Nacci, A.; D'Accolti, L. Steel Slag as New Catalyst for the Synthesis of Fames from Soybean Oil. Catalysts 2021, 11, 619. https://doi.org/10.3390/ catal11050619

Academic Editors: Yu-Chuan Lin and Nicoletta Ravasi

Received: 3 April 2021

Accepted: 9 May 2021

Published: 11 May 2021

Publisher's Note: MDPI stays neutral with regard to jurisdictional claims in published maps and institutional affiliations.

Copyright: (c) 2021 by the authors. Licensee MDPI, Basel, Switzerland. This article is an open access article distributed under the terms and conditions of the Creative Commons Attribution (CC BY) license (https:/ / creativecommons.org/licenses/by/ $4.0 /)$.

\begin{abstract}
For the first time, secondary steel slag, the material directly coming from ladle treatments, is used as a catalyst for the biodiesel production without undergoing any preliminary chemical or thermal modifications. Catalytic material 1, which has been pre-ground to sizes below 230 mesh, has been characterized for the surface textural properties and used as a catalyst in the transesterification of triglycerides of soybean oil to produce biodiesel. Reaction conditions were optimized by DOE method, revealing no interdependence between reaction parameters and results, and showed a catalytic activity comparable with that of an analogous slag-deriving catalyst reported in the literature.
\end{abstract}

Keywords: circular economy; heterogeneous catalysis; energy; FAME

\section{Introduction}

Growing energy demand and climate change are the two sides of the same coin representing one of the main challenge that mankind has been facing since the beginning of the 21st century. Diversifying the supply of energy fonts and materials, moving from a linear to a circular development model, is the winning strategy that avoids simultaneously the depletion of resources and the accumulation of waste.

Exploitation of biomasses is proving an invaluable source, especially for developing economies [1,2], as it offers multiple solutions both in terms of energy production and raw materials supply [2].

To date, biomass contributes to $10 \%$ of energy production mainly by means of firstgeneration biofuels, in particular bioethanol and biodiesel [3]. The latter derives from (trans) esterification reactions of (acids) triglycerides of vegetable and animal oils and is considered a relatively clean-burning, non-toxic, biodegradable, and renewable fuel.

Growing biodiesel demand has forced a refocusing of biomass supplying towards alternative feedstocks such as non-edible oils (soybean, jatropha and so on), algae, and waste lipid materials [4]. On the other hand, it stimulated a re-thinking in catalyst design aiming at using easy to prepare a heterogeneous catalyst, avoiding complex synthetic procedures that can be so expensive from an energy point of view (calcination, sintering processes etc.) that they can annul the benefits of its use.

Industrial wastes or by-products such as catalyst sources can be the solution for biodiesel production at a large scale, assuring low costs and environmental protection. A wide plethora of heterogeneous catalysts derived from biological and industrial waste materials together with their performance in biodiesel production have been recently reviewed $[5,6]$. Among the waste feedstocks, biomass and coal ash, industrial slag, mud 
and rock-based materials, as well as waste scale and waste shell matter have been investigated $[7,8]$. To date, very few reports have described catalytic investigations of iron processing or steelmaking by-products in transesterification reactions and biodiesel production. In 2012, Yamashita at al. reported the use of blast furnace slag as a precursor of a hydrocalumite catalyst suitable for transesterification of esters including triglycerides [9]. More recently, hydrotalcite-type mixed oxide catalysts were prepared from waste steel slag and employed in the synthesis of glycerol carbonate from glycerol and DMC [6]. In these cases, preliminary procedures of acid treatment followed by coprecipitation and calcination at $600-800{ }^{\circ} \mathrm{C}$ were required to obtain efficient catalysts.

In line with our continuous efforts aimed at developing new catalytic methods respectful of both green chemistry and circular economy principles, we decided to investigate the direct use of steel slag without their preliminary chemical or energy intensive treatments $[10,11]$. In this regard, we predicted that secondary steel slag coming from ladle treatments of the liquid steel, scarcely explored until now, could exhibit good catalytic performance in transesterification reaction of triglycerides due to the surface chemical composition ( $25 \%$ of basic $\mathrm{CaO}$ ). Herein, we report the study of their textural properties and catalytic performances in biodiesel production.

\section{Results and Discussion}

Transesterification catalyst was supplied by Arcelor Mittal (Italy Taranto Plant, Taranto, Italy) as a material directly deriving from the secondary slag in the steel making process after being ground in two steps reaching sizes below $230(0.063 \mathrm{~mm})$. The solid with this final grain was labeled as catalyst $\mathbf{1}$ and used without any further treatments (see Section 4.2).

\subsection{Catalyst Characterization and Surface Textural Properties}

Characterization of $\mathbf{1}$ was accomplished with the usual BET, BJH, SEM-EDX, and FTIR techniques. Specific surface area and pore sizes distribution of $\mathbf{1}$ were evaluated with Brunauer-Emmett-Teller (BET) and Barrett-Joyner-Halenda (BJH) methods [12]. Analyses in Table 1 confirmed that a change in pore sizes after reactions occurred, especially after the heat treatment at $400{ }^{\circ} \mathrm{C}$. Notably, after the third cycle, catalytic material displays a surface area 10 times larger than the pristine sample, and a doubled pore area. A similar trend was also recorded for the pore volume (about five times greater), which passes from 0.006 to $0.027 \mathrm{~m}^{2} / \mathrm{g}$.

Table 1. The pore structure parameters of catalyst 1.

\begin{tabular}{|c|c|c|c|c|}
\hline Catalyst 1 & $\begin{array}{l}\text { B.E.T. Area } \\
\left(\mathrm{m}^{2} / \mathrm{g}\right)\end{array}$ & $\begin{array}{l}\text { Pore Surface } \\
\text { Area }{ }^{*}\left(\mathrm{~m}^{2} / \mathrm{g}\right)\end{array}$ & $\begin{array}{l}\text { Pore Volume * } \\
\quad\left(\mathrm{cm}^{3} / \mathrm{g}\right)\end{array}$ & $\begin{array}{c}\text { Pore Radius * } \\
\text { Dv (r) (A) }\end{array}$ \\
\hline pristine & $0.463 \pm 0.007$ & 1.251 & 0.006 & 17.481 \\
\hline after 3rd cycle & $4.178 \pm 0.006$ & 2.131 & 0.027 & 19.609 \\
\hline $\begin{array}{c}\text { after thermic } \\
\text { treatment }\left(400{ }^{\circ} \mathrm{C}\right)\end{array}$ & $7.275 \pm 0.006$ & 8.357 & 0.034 & 19.615 \\
\hline
\end{tabular}

${ }^{*}$ Determined by BJH method.

In contrast, a similar macroscopic increase of the pores radius was not detected. A similar tendency was also observed for a sample obtained after thermic treatment $\left(400^{\circ} \mathrm{C}\right)$ accomplished the task of removing adsorbed organic material. Also, in this case, an increase of both surface area and pores volume without significant variation of the average radius of the pores themselves was recorded.

These results suggest that the transesterification process, most probably due to the reaction of basic sites (mainly $\mathrm{CaO}$ ) with methanol, caused, in the face of a minimal increase in the radius of the pores, a significant growth of their depth, a phenomenon that could explain the increase in the average surface area of the pores of the whole sample.

Isothermal data and pore sizes distribution (PSD) listed in Figure 1 clearly show a nonuniform material, as can be expected from a waste slag, composed by microporous 
(radii $<2 \mathrm{~nm}$ ) and mesoporous (radii until $100 \mathrm{~nm}$ ) domains that tended to collapse after the fourth recycle followed by thermal treatment at $400{ }^{\circ} \mathrm{C}$ (Figure 1C).
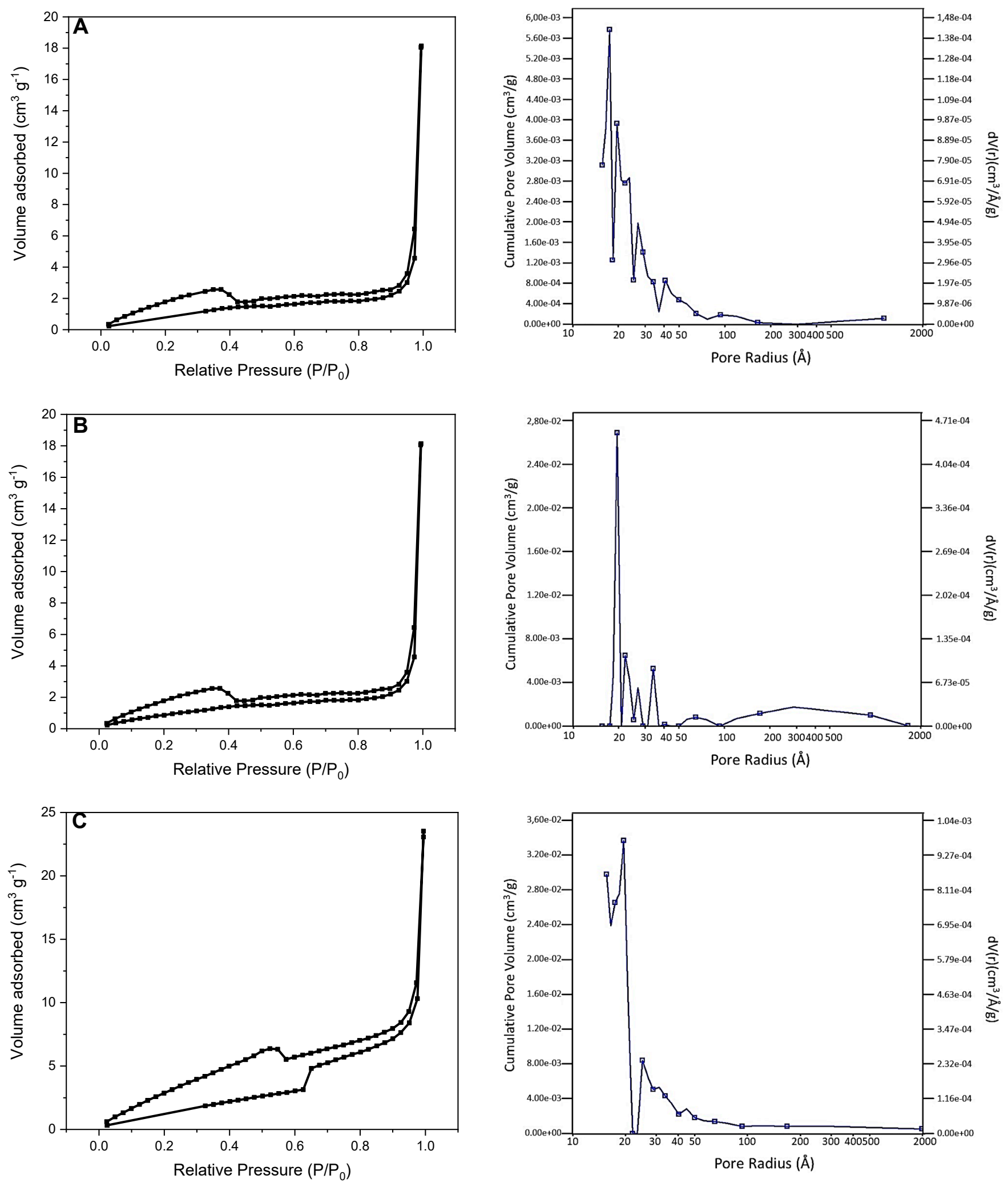

Figure 1. Isothermal data (left) and pore size distributions (right) of catalyst material: (A) pristine, (B) after fourth cycle, and $(\mathrm{C})$ after fourth cycle and thermic treatment at $400{ }^{\circ} \mathrm{C}$. 
The strong effect of calcination on textural properties of the catalyst was better highlighted by PSD analyses of pristine material treated at $400^{\circ} \mathrm{C}$. As can be seen from Figure S1, the micro and mesoporous structures completely disappeared leaving a totally macroporous material. This also suggests that thermal collapse phenomenon is somehow limited by the presence of absorbed organic material.

From SEM-EDX analyses it clearly emerged that catalyst $\mathbf{1}$ is an amorphous material mainly composed by $\mathrm{CaO}$ and Alumina (Figure 2A). Of particular interest is the presence of Fe and Mn in good percentages, as expected for steel slag. After the third cycle, the catalyst shows an elemental composition with an increased percentage of carbon, certainly due to adsorbed organic material that cannot be removed by simple washing. However, in this case, roughness and grain sizes do not appear quite different from pristine material (Figure 2B).
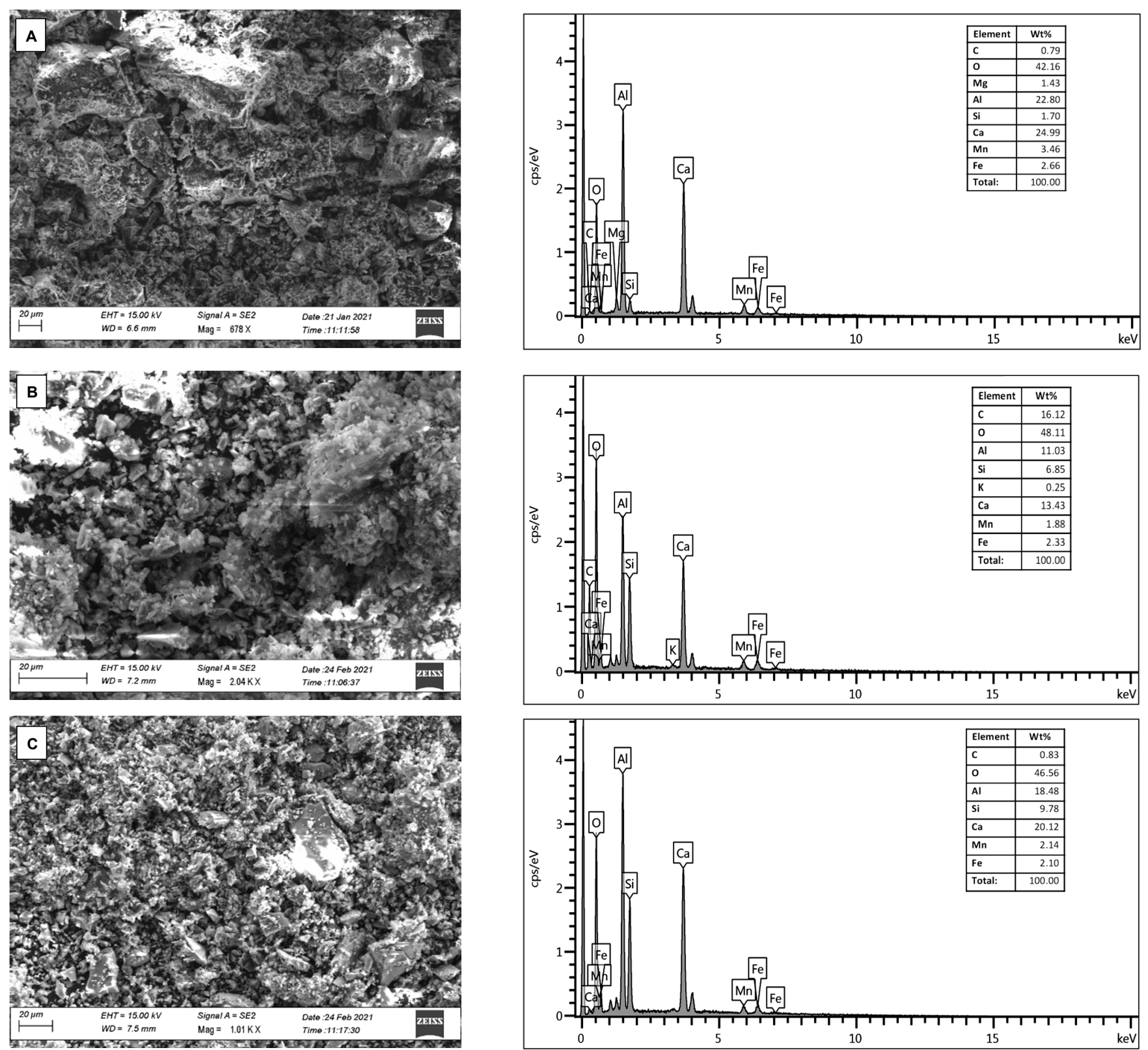

Figure 2. SEM EDX analyses of catalysts $\mathbf{1}$ (A) before catalytic reactions, (B) after the fourth cycle, and (C) after the fourth cycle and thermal treatment $\left(400^{\circ} \mathrm{C}\right)$. 
In contrast, catalytic material recovered after the fourth cycle, and thermal treatment at $400{ }^{\circ} \mathrm{C}$ displayed an elemental composition similar to that of pristine material but different roughness and grain sizes, indicating that morphologic structure collapsed with calcination (Figure 2C). An inspection of the images at lower magnification $(100 \mu \mathrm{m})$ reported in Figures S2-S4 (see Supplementary Material) clearly shows that after calcination the material agglomerates to give larger macroparticles and the mesoporous structure seems to collapse. This effect is confirmed by the SEM analysis performed on the pristine material after calcination (Figure S5).

Conversely, the analysis of mapping data highlights how $\mathrm{CaO}$, alumina, $\mathrm{Fe}$, and $\mathrm{Mn}$ remain equally distributed on the catalyst surface after reactions even after thermal treatment (see Figures S13, S17-S19 in Supplemental Materials).

ATR-FTIR analyses showed a broad band signal in the range $3450-3000 \mathrm{~cm}^{-1}$, together with signals at 1010 and $980 \mathrm{~cm}^{-1}$ due to O-H deformation vibrations [9]. Moreover, signals at 806 and $782, \mathrm{~cm}^{-1}$ are attributable to the symmetrical stretching of Si-O-Si. Finally, bands at 639 and $681 \mathrm{~cm}^{-1}$ can be assigned to the Al-O stretching mode (Figure 3A) [13,14].
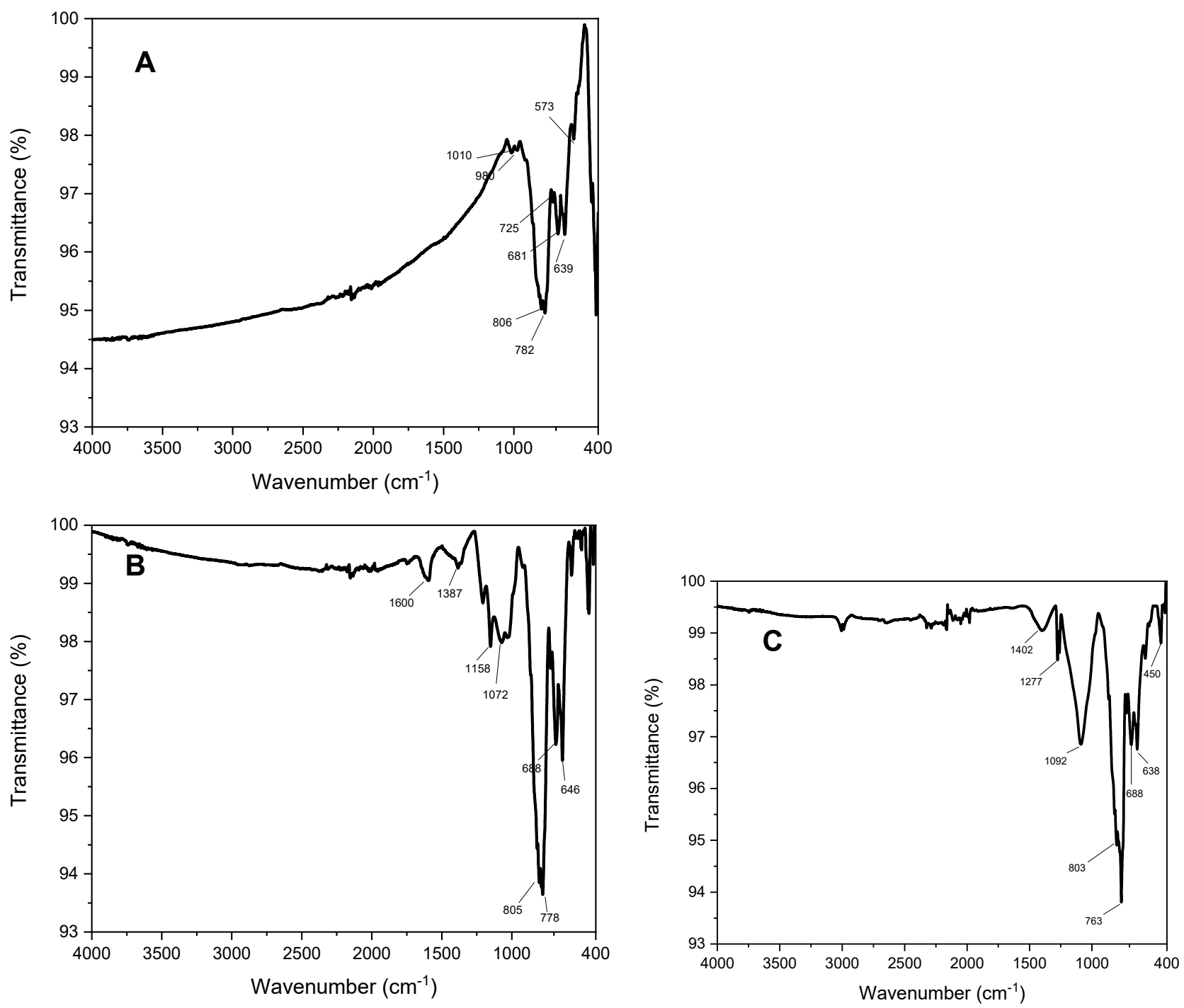

Figure 3. ATR-FTIR spectrum of catalyst $\mathbf{1}$ (A) as-prepared, (B) after fourth cycle, and (C) after fourth cycle and thermal treatment at $400{ }^{\circ} \mathrm{C}$. 
After the reaction, catalyst 1 was washed several times with methanol, dried in an oven at $70{ }^{\circ} \mathrm{C}$ for $12 \mathrm{~h}$, and reused for a new run. Further spectra were recorded after four cycles to investigate the decrease of activity, revealing that the catalyst continued to show the signals of the steel slag, but new bands appeared at 1660, 1387, 1156, and $107 \mathrm{~cm}^{-1}$, which is indicative of the presence of biodiesel and triglyceride esters signals (Figure 3B). To eliminate the organic material, $\mathbf{1}$ was subjected to a heat treatment at $400{ }^{\circ} \mathrm{C}$, which removed any trace of adsorbed organic material (Figure 3C).

\subsection{Catalytic Tests and Optimization of Transesterification Conditions}

The benchmark for evaluating the catalytic performances of $\mathbf{1}$ was the transesterification of triglycerides for the production of biodiesel (FAMEs). According to most reported procedures, catalytic experiments were conducted in the batch and the optimization of transesterification conditions proved to be crucial for increasing the biodiesel yields. The concentration of catalyst $\mathbf{1}$ along with the temperature and reaction time were very crucial factors for determining the rate and yield of transesterification, and thus both were optimized according to the traditional method, by varying one-by-one the reaction parameters, and the statistic DOE method, which is useful to reveal the interdependence between them. Catalysis conditions were surveyed on soybean oil as the model substrate, and reaction parameters were calibrated for processing $0.5 \mathrm{~mL}$ of oil $(0.415 \mathrm{~g})$ and $5 \mathrm{~mL}$ of methanol (Scheme 1).<smiles>[R]C(=O)OCC(COC([R])=O)OC([R])=O</smiles>

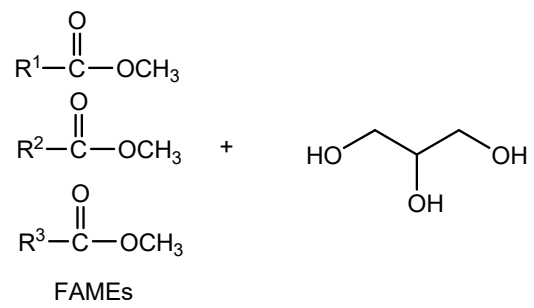

Scheme 1. Transesterification of triglycerides for the production of biodiesel (FAMEs).

Explorative experiments allowed to set the range values as follows: $\mathrm{T}=70-120^{\circ} \mathrm{C}$, catalyst wheight $(\mathrm{cw})=10-40 \mathrm{mg}$, Time $=6-18 \mathrm{~h}$. Results of one-by-one optimization reported in Table 2 reveal that at $70{ }^{\circ} \mathrm{C}$ reaction proceeds with very low yields (Table 2 entries 1-3).

Table 2. Optimization one-by-one of transesterification parameters ${ }^{(a)}$.

\begin{tabular}{ccccc}
\hline Entry & Temperature $\left({ }^{\circ} \mathbf{C}\right)$ & $\begin{array}{c}\text { Catalyst } \\
(\mathbf{m g})\end{array}$ & $\begin{array}{c}\text { Time } \\
(\mathbf{h})\end{array}$ & $\begin{array}{c}\text { Yield } \\
(\mathbf{6})\end{array}$ \\
\hline 1 & 70 & 10 & 6 & 1.70 \\
2 & 70 & 20 & 6 & 1.77 \\
3 & 70 & 40 & 6 & 0.60 \\
4 & 100 & 10 & 6 & 0.76 \\
5 & 100 & 20 & 6 & 3.98 \\
6 & 100 & 40 & 6 & 5.6 \\
7 & 120 & 10 & 6 & 31.75 \\
8 & 120 & 20 & 6 & 41.00 \\
9 & 120 & 40 & 6 & 44.89 \\
$\mathbf{1 0}$ & $\mathbf{1 2 0}$ & $\mathbf{2 0}$ & $\mathbf{1 2}$ & $\mathbf{1 0 0 . 0 0}$ \\
11 & 120 & 40 & 12 & 70.35 \\
12 & 100 & 20 & 12 & 56.57 \\
13 & 100 & 40 & 12 & 52.69 \\
$\mathbf{1 4}$ & $\mathbf{1 0 0}$ & $\mathbf{2 0}$ & $\mathbf{1 8}$ & $\mathbf{1 0 0 . 0 0}$ \\
\hline
\end{tabular}

(a) General conditions: soybean oil $0.5 \mathrm{~mL}(0.415 \mathrm{~g})$, methanol $4 \mathrm{~mL}(\mathrm{MeOH}$ / oil ratio $=8)$, catalyst 1, temperature and reaction times as reported. ${ }^{(b)}$ Determined by GC-MS and GC-FID analyses (see experimental section). 
By increasing the temperature up to $120{ }^{\circ} \mathrm{C}$, FAMEs yields increased until $44.89 \%$ (Table 2, entries 4-9). Increased catalyst amounts did not result in higher performance (Table 2, entries 6,9,11,13), while prolonged times proved to have a beneficial effect (Table 2, entries 10-14). From the bold font results in Table 2, which represent the optimized conditions, it clearly emerged that secondary slag displayed similar catalytic performance in transesterification reactions as those of the few analogous catalysts reported in the literature prepared through chemical and thermal pre-treatments of steel slag [9].

\subsection{Application of DOE Method}

For the optimization of transesterification parameters, 15 experiments were statistically required by Box-Behnken design (Figure 4). Ranges similar to those established in the previous experiments were chosen for applying the DOE method, and specifically $\mathrm{T}=70-120^{\circ} \mathrm{C}$, Time $=6-12 \mathrm{~h}$, and $\mathrm{cw}=10-40 \mathrm{mg}$ (see Section 2.2).

\begin{tabular}{|cccc|}
\hline Temperature & Reaction Time & Catalyst Weight & Yield* \\
\hline${ }^{\circ}$ C & Hrs & mg & $\%$ \\
\hline 95 & 12 & 25 & 55,5 \\
95 & 12 & 25 & 56,0 \\
95 & 12 & 25 & 54,3 \\
120 & 12 & 10 & 91,9 \\
120 & 18 & 25 & 100,0 \\
120 & 6 & 25 & 21,5 \\
70 & 18 & 25 & 18,4 \\
95 & 6 & 10 & 4,0 \\
95 & 18 & 40 & 100,0 \\
70 & 12 & 10 & 9,2 \\
70 & 6 & 25 & 2,5 \\
95 & 18 & 10 & 96,7 \\
95 & 6 & 40 & 6,5 \\
120 & 12 & 40 & 71,2 \\
70 & 12 & 40 & 3,5 \\
\hline
\end{tabular}

Figure 4. DOE experiments for evaluation of reaction parameters.

Results of the experiments reported in Figure 4 were analyzed by ANOVA to assess the "goodness of fit". In Table 3, the analysis of variance (ANOVA) is reported to evaluate the affecting factors.

From statistical parameters in Table 3, it clearly emerges that temperature and reaction time significantly influence the response at a confidential level of $95 \%$, because of the $p$-value being lower than 0.05 . In contrast, catalyst weight does not affect the system appreciably in the range investigated of $10-40 \mathrm{mg}$ ( $p$-value higher than 0.05$)$. Similarly, all the interactions between the three parameters, together with the quadratic terms, show a $p$-value higher than 0.05 , indicating that the three factors impact reaction in an independent manner. This trend is also confirmed by the slope of the main effect plot curves in Figure 5a and the standardized effect listed in the Pareto chart of Figure $5 b$. 
Table 3. Analysis of variance for reaction yields.

\begin{tabular}{ccccc}
\hline Source & Sum of Squares & Df & F-Ratio & $p$-Value \\
\hline A: Temperature & 7843.78 & 1 & 26.95 & 0.0035 \\
B: Reaction Time & 9870.13 & 1 & 33.91 & 0.0021 \\
C: Catalyst Weight & 47.5313 & 1 & 0.16 & 0.7028 \\
AA & 704.438 & 1 & 2.42 & 0.1805 \\
AB & 992.25 & 1 & 3.41 & 0.1241 \\
AC & 52.5625 & 1 & 0.18 & 0.6885 \\
BB & 130.168 & 1 & 0.45 & 0.5333 \\
BC & 1.0 & 1 & 0.00 & 0.9555 \\
CC & 21.9375 & 1 & 0.08 & 0.7946 \\
Total error & 1455.19 & 5 & & \\
Total (corr.) & 21110.4 & 14 & & \\
\hline
\end{tabular}

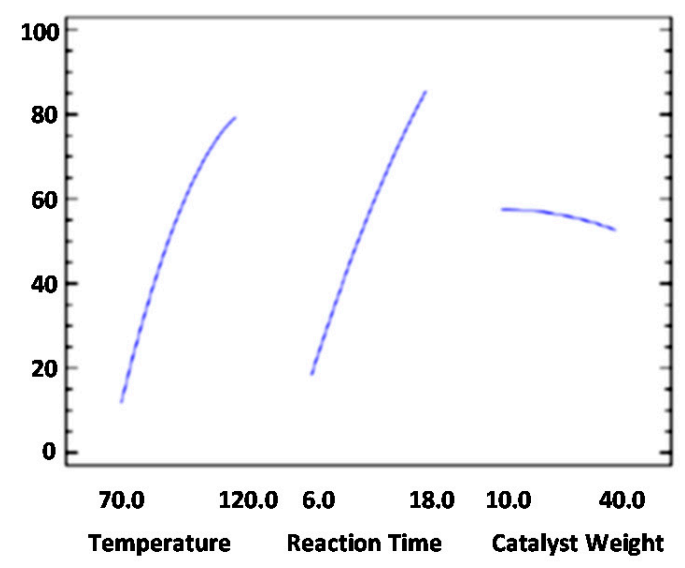

(a)

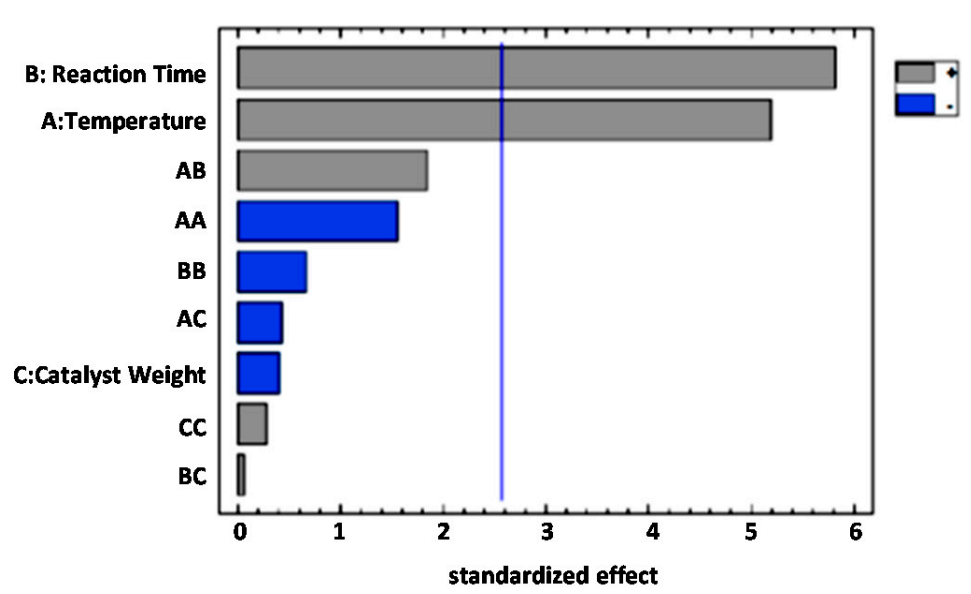

(b)

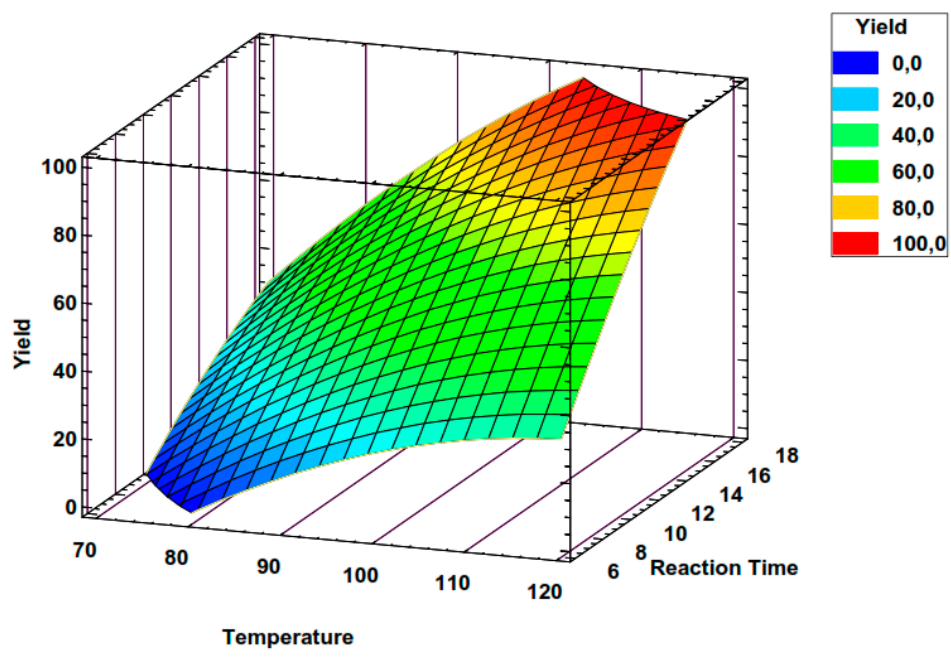

(c)

Figure 5. (a) Main effect plots for reaction yield, (b) standardized Pareto chart, and (c) response surface graph (catalyst weight $25 \mathrm{mg}$ ) of DOE method applied to steel slag catalytic performances. 
A plausible explanation of the negligible influence of catalyst weight can be given by assuming that the mass transfer diffusion within the methanol and oil phases, due to high mixture viscosity, can be considered the true rate-determining process in these transesterification reactions, as already reported [15]. This also explains why temperature and reaction time, being parameters that greatly influence viscosity and mass diffusion, affect the process in such a strong way.

Finally, response surface graph in Figure $5 c$ shows that maximum performances are obtained with a temperature of $109{ }^{\circ} \mathrm{C}$ and with a reaction time of $14 \mathrm{~h}$. Given that the catalyst weight is a negligible parameter, an average quantity of $20 \mathrm{mg}$ in the range investigated (10-40 mg) was chosen for further experiments.

Therefore, the statistical study highlights that similarly to the study conducted in the traditional way, there is no interdependence between the variables and the optimal conditions that are in line with those found in Section 2.2.

\subsection{Catalysts Recycle}

Recycling experiments were accomplished to evaluate the catalyst robustness. At this end, after the reaction was conducted under the optimized conditions reported in Table 1 (entry 14), catalyst 1 was washed with methanol, dried at $50{ }^{\circ} \mathrm{C}$, and reused for the next run. After the third cycle, the yield lowered to $67 \%$, and after the fourth one, catalytic activity dropped drastically (Table 4, entry 4). Further attempts to reactivate the catalyst, by removing the adsorbed organic material by calcination at $400{ }^{\circ} \mathrm{C}$, failed (Table 4 , entry fifth cycle).

Table 4. Recycle of catalyst $1^{(a)}$.

\begin{tabular}{ccccc}
\hline Cycles & $\begin{array}{c}\text { Temperature } \\
{ }^{\circ} \mathbf{C}\end{array}$ & $\begin{array}{c}\text { Time } \\
\text { (h) }\end{array}$ & Yield \% & Carbon Percentage (EDX) ${ }^{(\mathbf{b})}$ \\
\hline 1 & 100 & 18 & 100 & 0.72 \\
2 & 100 & 18 & 70 & 2.41 \\
3 & 100 & 18 & 67 & 26.14 \\
4 & 100 & 18 & 13 & \\
5 & 100 & 18 & 15 & \\
$-(\mathrm{d})$ & 100 & 18 & 24 & $(0.83)(\mathrm{c})$ \\
\hline
\end{tabular}

(a) Reaction conditions and monitoring as reported in Table 2 (see experimental section). ${ }^{\text {(b) }}$ Carbon percent of $\mathrm{C}$ after the cycle ${ }^{(\mathrm{c})}$. In brackets, carbon percent after calcination at $400^{\circ} \mathrm{C}$. , $^{(\mathrm{d})}$ Reaction carried out with pristine 1 pre-treated at $400{ }^{\circ} \mathrm{C}$.

A deeper inspection of SEM analyses and the experiments of pore sizes distribution (PSD) suggest that decreasing of catalytic performances after reuse is attributable, in the first instance, to the adsorbed organic material. This clearly emerged from the increment of carbon percentage after each cycle and workup to recovere the catalyst as reported in the last column of Table 4. (see also the EDX analysis in Supplemental Information (Figures S9-S12).

However, after the removal of organic material by calcination at $400{ }^{\circ} \mathrm{C}$, reactivation failed (fifth cycle) due to the collapse of the micro- and mesoporous structure of slag (Figure 1C and Figure S4), as confirmed by the low catalytic performances provided by pristine slag pre-treated at $400{ }^{\circ} \mathrm{C}$ (last reaction in Table 4).

Nevertheless, the net change of morphological structure after calcination at $400{ }^{\circ} \mathrm{C}$ cannot be ruled out as a possible reason for inactivation. An inspection of the SEM images at lower magnification $(100 \mu \mathrm{m})$ reported in Figures S2-S4 clearly shows that slag agglomerates to give larger macroparticles with a clear change of roughness and the formation of many fractures.

In contrast, the effect of surface elemental distribution can be excluded from the causes of inactivation, as it remains substantially unvaried after reactions and thermal treatment as revealed by mapping data already discussed in Section 2.2. 


\section{Conclusions}

Conversion of a by-product of the steel industry into high value added products represents one of the most important goals of circular economy. Steel slag, the large volume byproduct of iron-processing industries, is used to make a variety of composite materials in many countries, but only a few examples report its use in catalysis, providing that preliminary chemical and energy-intensive treatments are carried out $[5,6,9]$. In this work, for the first time, secondary steel slag, the material directly coming from ladle treatments, is used as a catalyst for the biodiesel production without undergoing any preliminary chemical or thermal modifications. The steel slag, which has been pre-ground to sizes below 230 mesh, has been characterized for the surface textural properties and used as a catalyst for biodiesel production from soybean oil. Reaction conditions were optimized by DOE method, revealing no interdependence between reaction parameters. The results showed a catalytic activity comparable with that of an analogous slag-deriving catalyst reported in the literature.

\section{Materials and Methods}

Solvents and reagents were purchased from Sigma-Aldrich and used as received. Soybean oil was a kind donation of Greenswitch industry (MT, Italy).

GC/MS analyses were run on a Shimadzu GLC 17-A instrument connected with a Shimadzu QP5050A selective mass detector using a SLB-5MS column $(30 \mathrm{~m} \times 0.25 \mathrm{~mm}$ id, film thickness $0.25 \mu \mathrm{m})$. Mass spectra were performed in EI mode $(70 \mathrm{eV})$ and conversions were determined using 2,5-dimethylanisole as an external standard.

ATR-FTIR spectra of catalyst 1 were recorded in the range of $400-4000 \mathrm{~cm}^{-1}$ on a Pekin Elmer spectrometer instrument.

BET (Brunauer-Emmett-Teller)-specific surface area was obtained by $\mathrm{N}_{2}$ adsorptiondesorption method on powder samples using an Autos orb IQ Chemo TCD (Quantachrome Instruments, Boynton Beach, FL, USA). Samples (500 mg) were pre-treated at $77 \mathrm{~K}$ for $2 \mathrm{~h}$ before $\mathrm{N}_{2}$ adsorption.

SEM-EDX analyses were performed with an electron microscope FESEM-EDX Carl Zeiss Sigma 300 VP. The samples were fixed on aluminum stubs and then sputtered with graphite using a Sputter Quorum Q150. Additionally, the chemical composition was determined by EDX under the scanning electron microscope and X-rays diffraction.

\subsection{Source of Steel Slag Catalyst 1}

The steel slag was supplied by Arcelor Mittall Italia Company (Taranto, Italy). This material constitutes the secondary slag arising from ladle treatments that are performed on the liquid steel iron in order to improve the quality characteristics of the final product. The slag was cooled by natural convection and subsequently ground in two steps to reach the particle size of 230 mesh $(0.063 \mathrm{~mm})$.

In particular, the slag was pre-ground in a jaw mill and reduced to a size below $10 \mathrm{~mm}$. Then, it was further ground with a cup mill to reach sizes below 230 mesh $(0.063 \mathrm{~mm})$. This final grain size was guaranteed by checking with a certified sieve. The material thus obtained, labeled as catalyst 1 , was tested without any further treatment in the transesterification reaction of triglycerides for biodiesel production.

\subsection{Transesterification Experiments}

The procedure is similar to that adopted in a previous work [4]. A $10 \mathrm{~mL}$ screw cap glass vial equipped with a magnetic bar was charged with methanol $(4 \mathrm{~mL})$, soybean oil $(0.5 \mathrm{~mL}, 415 \mathrm{mg})$, and the proper amount of catalyst 1 . Then, the vial was sealed and heated under stirring at the proper temperature. After the reaction, the mixture was cooled to room temperature, transferred into a centrifuge tube, and subjected to $3500 \mathrm{rpm}$ for $15 \mathrm{~min}$. The catalyst layered to the bottom, while the surnatant organic phase was recovered by pipette. The catalyst was washed with $2 \times 4 \mathrm{~mL}$ of pure methanol and dried at $50{ }^{\circ} \mathrm{C}$ promptly to be reused. The washing phases and organic surnatant were combined, the 
solvent removed by evaporation and re-dissolved into $5 \mathrm{~mL}$ of ethyl acetate. Then, $100 \mu \mathrm{L}$ of hexadecane (standard) were added for GC-MS analyses.

\subsection{Experimental Design and Data Analysis}

The selected reaction parameters "temperature, time and weight of catalyst" were optimized with the experimental method (DOE), using the Box-Behnken design by the Statgraphics ${ }^{\circledR}$ Centurion XVII software. As reported in Figure 4, 15 completely randomized experiments were chosen to have protection against the effects of hidden variables. The DOE provided information regarding the eventual interaction between the variables and on the influence of parameters selected in accordance to a quadratic polynomial model of general formula:

$$
Y=\beta_{0}+\beta_{1} x_{1}+\beta_{2} x_{2}+\beta_{3} x_{3}+\beta_{12} x_{1} x_{2}+\beta_{23} x_{2} x_{3}+\beta_{13} x_{1} x_{3}+\beta_{11} x_{1}{ }^{2}+\beta_{22} x_{2}{ }^{2}+\beta_{33} x_{3}^{2}
$$

where $x_{1}, x_{2}$ and $x_{3}$ are the experimental variables (T, T and \%wt. cat.), while $\beta_{0}, \beta_{1}, \beta_{2}$, $\beta_{3}, \beta_{12}, \beta_{23}, \beta_{13}, \beta_{11}, \beta_{22}$, and $\beta_{33}$ are the coefficients of polynomial model and $Y$ is the response (reaction yield). $\left(R^{2}=0.951\right)$

Yield $=-264.19+4.12083 \mathbf{T}+2.38056 \mathbf{R T}+1.25231 \mathbf{C W}-0.0171667 \mathbf{T}^{2}+0.06 \mathbf{T}^{*} \mathbf{R T}-0.0116667 \mathbf{T} \times \mathbf{C W}^{*} 0.120949 \mathbf{R} \mathbf{T}^{2}-0.00277778 \mathbf{R T} \mathbf{C W}^{*}-0.00546296 \mathbf{C W}$

where $\mathbf{T}$ is the temperature, $\mathbf{R T}$ is reaction time, and $\mathbf{C W}$ is catalyst weight.

Supplementary Materials: The following are available online at https:/ / www.mdpi.com/article/10 $.3390 /$ catal11050619/s1. The following are available online B.E.T. analysis of pristine catalyst $\mathbf{1}$ after thermic treatmen(S1), Supplemental SEM images at $100 \mu \mathrm{m}$ of catalyst 1 (S2-S5), Supplemental SEM images at $20 \mu \mathrm{m}$ of recycle of catalyst 1 (S6-S8), Supplemental EDX analysis of recycle of catalyst 1 (S9-S12), Mapping images of catalyst and of recycle of catalyst 1 (S13-S19).

Author Contributions: Conceptualization, L.D., C.F. and A.N., methodology, M.C. and D.C., investigation, O.L. and A.A.; data curation, M.C., A.M. and D.C.; writing-original draft preparation, L.D.; writing-review and editing, A.N., C.F. and R.A., supervision, L.D. All authors have read and agreed to the published version of the manuscript.

Funding: This work is partially supported by funds from European Union -19 FESR "PON Ricerca e Innovazione 2014-2020. Progetto: 20 Energie per l'Ambiente TARANTO-Cod. ARS01_00637".

Data Availability Statement: Data available in supplemental materials.

Acknowledgments: Thanks to Tommaso Castiglia (bachelor student for collaboration in experimental procedure). Thanks to Arcelor Mittal Italia Taranto for collaboration.

Conflicts of Interest: The authors declare no conflict of interest.

\section{References}

1. Agarwal, A.K. Biofuels (alcohols and biodiesel) applications as fuels for internal combustion engines. Prog. Energy Combust. Sci. 2007, 33, 233-271. [CrossRef]

2. Demirel, Y. Biofuels. Compr. Energy Syst. 2018, 1, 875-908. [CrossRef]

3. Pradhana, P.; Mahajanib, S.M.; Arora, A. Production and utilization of fuel pellets from biomass: A review. Fuel Process. Technol. 2018, 181, 215-232. [CrossRef]

4. Casiello, M.; Catucci, L.; Fracassi, F.; Fusco, C.; Laurenza, A.G.; di Bitonto, L.; Pastore, C.; D'Accolti, L.; Nacci, A. ZnO/Ionic Liquid Catalyzed Biodiesel Production from Renewable and Waste Lipids as Feedstocks. Catalysts 2019, 9, 71. [CrossRef]

5. Alagumalai, A.; Mahian, O.; Hollmann, F.; Zhang, W. Environmentally benign solid catalysts for sustainable biodiesel production: A critical review. Sci. Total. Environ. 2021, 768, 144856. [CrossRef] [PubMed]

6. Liu, G.; Yang, J.; Xu, X. Synthesis of hydrotalcite-type mixed oxide catalysts from waste steel slag for transesterification of glycerol and dimethyl carbonate. Sci. Rep. 2020, 10, 10273. [CrossRef] [PubMed]

7. He, Y.; Luo, Q.; Hu, H. Situation analysis and countermeasures of China's fly ash pollution prevention and control. Procedia Environ. Sci. 2012, 16, 690-696. [CrossRef]

8. Youcai, Z.; Ash, B.; Ash, F. Pollution Control and Resource Recovery: Municipal Solid Wastes Incineration, 1st ed.; Heinemann, B., Ed.; Elsevier: Oxford, UK, 2017; Volume 1, pp. 1-59. [CrossRef] 
9. Kuwahara, Y.; Tsuji, K.; Ohmichi, T.; Kamegawa, T.; Moria, K.; Yamashita, H. Transesterifications using a hydrocalumite synthesized from waste slag: An economical and ecological route for biofuel production. Catal. Sci. Technol. 2012, 2, $1842-1851$. [CrossRef]

10. Casiello, M.; Iannone, F.; Cotugno, P.; Monopoli, A.; Cioffi, N.; Ciminale, F.; Trzeciak, A.M.; Nacci, A. Copper(II)-catalysed oxidative carbonylation of aminols and amines in water: A direct access to oxazolidinones, ureas and carbamates. J. Mol. Catal. A Chem. 2015, 407, 8-14. [CrossRef]

11. Massaro, M.; Casiello, M.; D'Accolti, L.; Lazzara, G.; Nacci, A.; Nicotra, G.; Noto, R.; Alberto Pettignano, A.; Spinella, C.; Riela, S. One-pot synthesis of $\mathrm{ZnO}$ nanoparticles supported on halloysite nanotubesfor catalytic applications. Appl. Clay Sci. 2020, 189, 10557. [CrossRef]

12. Caputo, D.; Casiello, M.; Milella, A.; Oberhauser, W.; Maffezzoli, A.; Nacci, A.; Fusco, C.; D'Accolti, L. Deep Control of Linear Oligomerization of Glycerol Using Lanthanum Catalyst on Mesoporous Silica Gel. Catalysts 2020, 10, 1170. [CrossRef]

13. Zviagina, B.B.; Drits, V.A.; Dorzhieva, O.V. Distinguishing Features and Identification Criteria for K-Dioctahedral 1M Micas (Illite-Aluminoceladonite and Illite-Glauconite-Celadonite Series) from Middle-Infrared Spectroscopy Data. Minerals 2020, 10, 153. [CrossRef]

14. Madejova, J. FTIR techniques in clay mineral studies. Vib. Spectrosc. 2003, 31, 1-10. [CrossRef]

15. Ho, W.W.S.; Ng, H.K.; Gan, S.; Tan, S.G. Evaluation of palm oil mill fly ash supported calcium oxide as a heterogeneous base catalyst in biodiesel synthesis from crude palm oil. Energy Convers. Manag. 2014, 88, 1167-1178. [CrossRef] 